\title{
TRANSMISSIBILIDADE DO VIRUS DO MOSAICO COMUM DA SOJA (VMCS) POR INTERMÉDIO DAS SEMENTES DE SOJA (Glycine max (L.) Merrill)
}

\author{
A.S.do R. BARROS ${ }^{1}$ \& W.R. da SILVA ${ }^{2}$
}

\begin{abstract}
RESUMO: Diante da dispersão do vírus VMCS nas lavouras brasileiras de soja, o presentetrabalho foi conduzido procurando verificar a transmissibilidade do patogeno pelas sementes portadoras do sintoma ("mancha café") característico da doenca. Para tanto, material proveniente de campos contaminados foi testado quanto às porcentagens de emergência e infecção das plântulas. Os resultados obtidos permitiram concluir que o patógeno é transmitido por sementes, ainda que estas estejam livres de sintomas; contudo, apesar da inexistência de efeitos sobre a emergência, a elevação da frequência de sementes com "mancha café" tende a ampliar o número de plantulas contaminadas.
\end{abstract}

Descritores: senente, mancha café, vírus do mosaico comum da soja.

\section{TRANSMISSION OF SOYBEAN MOSAIC VIRUS (SMV) BY SOYBEAN SEEDS (Glycine max (L.) Merriil).}

\begin{abstract}
In view of the long-range dissemination of the virus SMV in Brazilian soybean fields, this research was conserned with the transmission of the pathogen by seeds that show seedcoat mottling. Seeds proceeding from contaminated fields were submitted to emergence tests and examination of infected seedlings. The results indicated that the pathogen is transmited through the seeds even when they do not show seedcoat mottling; although no particular effect was found on emergence percentage, the use of mottled seeds tends to increase the number of infected seelings.
\end{abstract}

Key Words: soybean seeds, seedcoat mottilling, soybean mosaic virus.

\section{INTRODUÇÃO}

O "Mosaico comum da soja" é uma doenca, causada pelo virus VMCS, considerada como plenamente dispersa nas lavouras brasileiras de soja (YORINORI, 1982). Os seus prejuízos potenciais, em termos produtivos, partem de valores nulos e chegam a atingir perdas de até 25\% (LUCENA et al, 1983).

A transmissibilidade do vírus por intermédio da semente, descrita pela primeira vez por GARDNER e KENDRICK (1921), é um mecanismo genericamente aceito e chega a provocar reduções apreciáveis na germinação (COSTA, 1977).

Contudo, a correlação existente entre a sintomatologia nas sementes, representada pelo derramamento do hilo ("mancha café"), e a infecção das plântulas, não se encontra adequadamente definida. Esta dificuldade pode estar associada ao grande número de variáveis envolvidas no processo, que acham-se ligadas ao cultivar (COSTA, et al., 1970; COSTA, 1977; ALMEIDA e MIRANDA, 1978 e COSTA et al., 1981), à posição da semente na planta (LIMA NETO, 1981), às condições do ambiente com destaque para a população de afídios (LUCENA et al., 1983 e YORINORI, 1985) e à época da infecção da planta mãe segundo sua idade (COSTA et al., 1970 e LIMA NETO, 1981).

Em decorrência desta situação do conhecimento, há a necessidade da intensificação de estudos que envolvam as sementes já colhidas com o objetivo de atingir resultados que, mesmo aproximadamente, permitam 0 aprimoramento de

\footnotetext{
'Instituto Agronômico do Paraná (IAPAR) - Caixa Postal, 1331 - CEP: 86001 - LONDRINA-PR.

2 Escola Superior de Agricultura "Luiz de Queiroz"(ESALQ/USP) - Caixa Postal, 9 - CEP: 13418-900 PIRACICABA-SP.
} 
padrões sanitários vigorantes (CESM/SP, 1983 e CESM/PR, 1984) em sistemas organizados de produção.

Dessa maneira, o presente estudo propõe-se a fornecer informações adicionais sobre $o$ tema, procurando verificar a transmissibilidade do patógeno em sementes de soja, provenientes de lotes oriundos de campos contaminados, e a contribuir para a padronização do teste de transmissibilidade.

\section{MATERIAL E MÉTODOS}

O trabalho foi conduzido durante o mês de setembro de 1986, nas instalações do laboratório de Análise de Sementes do Departamento de Agricultura e Horticultura da Escola Superior de Agricultura " Luiz de Queiroz", em Piracicaba, Estado de São Paulo.

Foram utilizadas sementes de soja, classe básica, das cultivares BR-6 e Bossier, provenientes da Fundação Instituto Agronômico do Paraná-IAPAR e produzidas na região de Ponta Grossa-PR durante a safra 1985/86, em campo cujo histórico indicava a ocorrência de mosaico comum da soja. Para cada cultivar empregaram-se 2 lotes.

Cada lote foi representado por três tratamentos que, obtidos a partir da amostra original, tiveram como frequências de derramamento do hilo as indicadas na tabela 1 .

De cada tratamento, foram coletadas quatro repetições de 50 sementes que, a seguir, foram semeadas em caixas plásticas com solo a uma profundidade média de $2 \mathrm{~cm}$. A água adicionada ao solo foi equivalente a $50 \%$ da capacidade de campo (total da água retida após a livre percolação).

As caixas permaneceram no interior de laboratório, presumivelmente livre de afídios, por um período experimental de 13 dias, sem controle das condições de ambiente.

A emergência, avaliada no $5^{\circ}$ dia após a semeadura, foi estimada pela porcentagem de plântulas que apresentavam os cotilédones totalmente expostos acima da superfície do solo.

A avaliação das plântulas infectadas, realizadas no $8^{\circ}$ dia após a avaliação da emergência, considerou a porcentagem de plântulas que, emersas, apresentavam sintomas de mosaico comum da soja nas folhas primárias, ou seja, clareamento das nervuras, mosaicos, deformações e encarquilhamento (ALMEIDA e MIRANDA, 1978).

O delineamento experimental utilizado foi o inteiramento casualizado com 3 tratamentos e 4 repetições. Para fins de análise estatística, os dados de emergência foram transformados em are sen de raíz quadrada de $\% / 100$ e os de plântulas infectadas em raíz quadrada de $x+0,5$. As médias foram comparadas pelo teste de Tukey ao nível de $5 \%$ de probabilidade.

\section{RESULTADOS E DISCUSSÃO}

A realização completa do trabalho, em condições de laboratório fechado, teve como objetivo principal dificultar a transmissão do vírus (VMCS) por afídios.

As duas cultivares empregadas são recomendadas para o Estado do Paraná (OCEPAR/ EMBRAPA, 1986) e ambas apresentam constantes problemas de recusa de lotes por presença de "mancha café" acima dos padrões estabelecidos pela CESM/PR (1984). Apesar da BR-6 ser considerada como suscetível e a Bossier moderadamente suscetivel, os dois lotes utilizados dessa última cultivar estariam fora dos padrões de comercialização previstos tanto pela CESM/SP (1983), quanto pela CESM/PR (1984).

Os dados obtidos para a emergência das plântulas estão apresentados na tabela 2. A sua análise não permite e detecção de quaisquer variações significativas e nem, tão pouco, de tendências que pudessem dar indicações de desempenho diferencial entre os tratamentos. Esta constatação, por sua vez, contrataria parcialmente os resultados obtidos por COSTA (1977), que destacam prejuízos, advindos do patógeno, sobre a germinação.

Os valores encontrados para a frequência de plântulas infectadas acham-se indicados na tabcla 3 . Estes permitem a verificação de diferenças significativas, entre tratamentos, nos lotes representantes da culturar Bossicr; enquanto o denominado como $\mathrm{C}$ apresentou maior infecção no tratamento "100\%" de mancha café", quando comparado aos demais, o lote D mostrou superioridade de infecção do tratamento "100\% de mancha calé" apenas sobre o tratamento "0\% de mancha café".

Paralelamente, independentementeda cultivar e das constatações estatísticas, é possível obscrvar que todos os tratamentos, inclusive "0\% de mancha café", provocaram transmissão do vírus, com tendência de agravamento seguindo a elevação da frequência do sintoma nas sementes.

Contudo, em termos numéricos, a transmissibilidade dos tratamentos "original" e "100\% de mancha café" é sensivelmente inferior à taxa de ocorrência do sintoma nas sementes o que, por sua vez, sugere dificuldades de previsão de infecções nas plântulas a partir do exame visual das sementes. 
Tabela 1 - Denominação dos tratamentos e respectivas ocorrências percentuais de derramamento do hilo ("mancha café"), segundo os diferentes lotes estudados.

\begin{tabular}{||lcccc|}
\hline \multirow{2}{*}{ Tratamentos } & \multicolumn{4}{c|}{ Cultivar (lote) } \\
\cline { 2 - 5 } & BR-6 (A) & BR-6 (B) & Bossier (C) & Bossier (D) \\
\hline Original & 10,7 & 10,4 & 39,0 & 34,2 \\
0\% de mancha café & 0,0 & 0,0 & 0,0 & 0,0 \\
$100 \%$ de mancha café & 100,0 & 100,0 & 100,0 & 100,0 \\
\hline
\end{tabular}

Tabela 2 - Emergência de plântulas de soja (\%), a partir de sementes com três níveis de sintomas de derramamento do hilo. Piracicaba, 1986.

\begin{tabular}{||lcccc||}
\hline \multirow{2}{*}{ Tratamentos } & \multicolumn{5}{c|}{ Cultivar (lote) } \\
\cline { 2 - 5 } & BR-6 (A) & BR-6 (B) & Bossier (C) & Bossier (D) \\
\hline Original & $95,0 \mathrm{a}$ & $83,5 \mathrm{a}$ & $96,0 \mathrm{a}$ & $95,5 \mathrm{a}$ \\
0\% de mancha cafe & $95,5 \mathrm{a}$ & $80,5 \mathrm{a}$ & $98,5 \mathrm{a}$ & $91,5 \mathrm{a}$ \\
$100 \%$ de mancha cafe & $95,5 \mathrm{a}$ & $90,0 \mathrm{a}$ & $96,5 \mathrm{a}$ & $95,0 \mathrm{a}$ \\
\hline $\mathrm{CV}(\%)$ & 4,7 & 6,3 & 5,2 & 4,6 \\
\hline
\end{tabular}

abela 3 - Porcentagens de plântulas de soja com sintomas de mosaico comum, a partir de sementes com três níveis de sintomas de derramamento do hilo. Piracicaba, 1986.

\begin{tabular}{|lrrrc||}
\hline \multirow{2}{*}{ Tratamentos } & \multicolumn{4}{c|}{ Cultivar (lote) } \\
\cline { 2 - 5 } & BR-6 (A) & BR-6 (B) & Bossier (C) & Bossier (D) \\
\hline Original & $1,58 \mathrm{a}$ & $1,87 \mathrm{a}$ & $3,61 \mathrm{a}$ & $2,61 \mathrm{ab}$ \\
0\% de mancha cafe & $1,06 \mathrm{a}$ & $0,67 \mathrm{a}$ & $2,53 \mathrm{a}$ & $2,22 \mathrm{a}$ \\
$100 \%$ de mancha cafe & $2,60 \mathrm{a}$ & $2,79 \mathrm{a}$ & $8,26 \mathrm{~b}$ & $5,24 \mathrm{~b}$ \\
\hline $\mathrm{CV}(\%)$ & 22,40 & 29,98 & 14,52 & 17,97 \\
\hline
\end{tabular}

\section{CONCLUSÕES}

- O vírus (VMCS) do "mosaico comum da soja" é transmitido por sementes.

- A inexistência de derramamento do hilo ("mancha café") não indica ausência do patógeno viável na semente.

- A semente portadora de "mancha café" não é necessariamente um veículo de transmissão do vírus à plântula.
- Elevação da ocorrência de "mancha café" tende a aumentar a frequência de plântulas com sintomas.

- Não foram detectáveis prejuízos na emergência como decorrência da presença de "mancha café".

\section{REFERÊNCIAS BIBLIOGRÁFICAS}

ALMEIDA, A.M.R. \& MIRANDA, L.C. Aspectos da ocorrência do mosaico comum da soja em sementes e sua transmissibilidade. Fitopatologia Brasileira. Resumos do $11^{\circ}$ Congresso da 
Sociedade Brasileira de Fitopatologia, Viçosa, 1978. Brasilia, 3: 74, 1978.

\section{COMISSÃO ESTADUAL DE SEMENTES E MUDAS} DO ESTADO DO PARANÁ. Normas de Produção de Sementes; básica, registrada, certificada e fiscalizada. Curitiba, Secretária de Agricultura, 1984. 110p.

\section{COMISSÃO ESTADUAL DE SEMENTES E MUDAS} DO estado de SÃo paulo. Produção de sementes fiscalizadas; normas. São Paulo, Delegacia Federal de Agricultura, 1983. 83p.

COSTA, A.S. Investigações sobre moléstias da soja no Estado de São Paulo. Summa Phytopatologica, Piracicaba, 3: 3-30, 1977.

COSTA, A.S.; MIRANDA, M.A.C.; MASCARENHAS, H.A.A. Relação de algumas cultivares de soja em estudo no Instituto Agronômico ao vírus do mosaico comum. In: SEMINÁRIO NACIONAL DE PESQUISA DE SOJA, 2.,Brasilia, 1981. ANAIS. Londrina, EMBRAPA/CNPSO, 1981. v.2, p.262-4.

COSTA, A.S.; MIYAZAKA, S.; KIIHL, R.A.S.; DEMATTÊ, J.O. Moléstias de vírus da soja em São Paulo. In: SIMPÓSIO BRASILEIRO DE SOJA, 1., Campinas, 1970. p.48-50.

GARDNER, M.W. \& KENDRICK, J.B. Soybean mosaic. Journal of Agricultural Research, Washington, 22: 111-4, 1921.

LIMA NETO, V.C. Influencia da localização das vagem na planta e da posição das sementes nas vagens, na produção de sementes manchadas e na transmissão do vírus do mosaico comum da soja, em soja. Revista do Setor de Ciências Agrárias, Curitiba, 3: 13-9, 1981.

J.A.M.; CASELA, C.R.; GASTAL, M.F.C. Doenças da soja. In: VERNETT, F.J., coord. Soja. Campinas, Fundação Cargill, 1983. v.1, p.339463.

ORGANIZAÇÃO DAS COOPERATIVAS DO ESTADO DO PARANÁ. Recomendações técnicas para a cultura da soja no Paraná; 1986/87. Cascavel, OCEPAR; EMBRAPA/ CNPSO, 1986. 68p. (Documentos, 19)
YORINORI, J.T. Doenças da Soja no Brasil. In: FUNDAÇÃo CARGILL. A soja no Brasil Central. 2.ed. Campinas, 1986. v.1, p.301-64

YORINORI. J.T. Estudo comparativo sobre a transmissilidade de "mancha café" em casa de vegetação e em campo. In: EMBRAPA/CENTRO NACIONAL DE PESQUISA DA SOJA. Resultados de pesquisa de soja; 1984/85. Londrina, 1985. p.231-4. (Documentos,15)
Trabalho entregue para publicação em 03.10.91

Trabalho aprovado para publicação em 17.02.92 